\title{
H20slim $\circledast$, the water-soluble polysaccharides from Agaricus bisporus, significantly reduces body weight and improves lipid parameters in overweight humans in a randomized double-blind vs placebo study
}

\author{
Gemma Clemente-Ramos*, Cristina Benítez-Gil, Gemma Lopez Diaz-Cano and Eva Esquinas- \\ Trenas
}

QUIMIFARMA 2007SL. C/Carlos I. La Villa De Yuncos 45210 - (Yuncos) - Toledo, Spain

*Corresponding author: Gemma Clemente-Ramos, QUIMIFARMA 2007SL. C/ Carlos I. La Villa De Yuncos 45210 - (Yuncos) - Toledo, Spain

To Cite This Article: Gemma Clemente-Ramos, H2Oslim $®$, the water-soluble polysaccharides from Agaricus bisporus, significantly reduces body weight and improves lipid parameters in overweight humans in a randomized double-blind vs placebo study. 2020 - 7(6). AJBSR. MS.ID.001205. DOI: 10.34297/AJBSR.2020.07.001205.

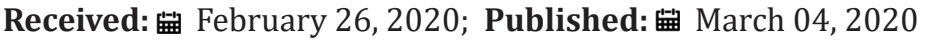

\begin{abstract}
In vitro tests demonstrated that the water-soluble polysaccharides from Agaricus bisporus is capable of trapping fat through a cationic polymer trapping net in contact with water. The fat trapping capability of this cationic net could favorably impact on blood lipid levels and diminishing cardiovascular risk factors. The aim of the study was to understand the effects of $\mathrm{H} 20$ slim ${ }^{\circledR}$, on body weight and associated metabolic parameters in overweight human volunteers. The study participants comprised of 100 healthy, overweight volunteers (defined as BMI 25-30 kg/m2) randomly divided into two groups. The groups received on a daily basis, either $400 \mathrm{mg}$ of $\mathrm{H} 20$ slim ${ }^{\circledR}$ or matching placebo in a double blinded. Participants were evaluated at baseline, 4, 8 and 12 weeks of the study. Significant improvements in body weight, waist circumference as well as plasma total cholesterol, LDL cholesterol, were observed in the H2Oslim ${ }^{\circledR}$ group (H-group) compared with the placebo group (P-group). The results here reported revealed that the supplementation of $\mathrm{H} 2 \mathrm{Oslim}{ }^{\circledR}$ seems a useful tool in dealing with obesity and hyperlipidemia
\end{abstract}

\section{Introduction}

Obesity is one of the major health concerns worldwide affecting approximately all physiological roles of the body. It increases the risk for multiple chronic conditions, such as cardiovascular disease [1,2], diabetes mellitus, different kinds of cancers [3], some musculoskeletal disorders [4], and poor mental health [5]. Also, studies show that obesity can have negative influences on the quality of life, healthcare costs and work productivity [6,7]. The World Health Organization (WHO) has estimated that obesity affects 500 million people worldwide and it could potentially increase to one billion people globally by 2030 [8,9]. The global obesity epidemic and ageing population are major public health concerns. With excess weight becoming increasingly 'normal', public perceptions of what constitutes a healthy body weight have become more inaccurate over time, with increasing numbers perceiving a body mass index (BMI) in the overweight or obese range ( $\geq 25 \mathrm{~kg} / \mathrm{m} 2$ ) to be 'about right'. The numbers of older adults with overweight (BMI $25-29.9 \mathrm{~kg} / \mathrm{m} 2$ ) and obesity (BMI $\geq 30 \mathrm{~kg} /$ $\mathrm{m} 2$ ) are rising rapidly, due to concurrent increases in the number of adults who reach older age and the proportion who carry excess weight. Understanding how older adults perceive their own weight status, and the extent to which this is influenced by their age and health status, is important for informing targeted recommendations and interventions to promote healthy weight in later life. Although overweight and obesity result from a combination of causes, overconsumption of high-energy foods is considered as the primary cause of obesity [10].

In addition, evidence showed that factors such as lack of physical activity, lack of sleep, sedentary lifestyle and high level of stress could also increase the risk of obesity [11,12]. individual, social and behavioral determinates of obesity $[13,14]$ may increase 
the risk of obesity conjointly or independently. For example, an obesogenic behavior like lack of physical activity may be influenced by individual and social factors such as genetic, biological, marital, educational and occupational factors[15,16].The use of animalderived ingredients as chitosan and may other botanical extracts to diminish the lipid absorption has been widely reported [17-26]. The reduction of the adipose tissue seems a clear target to reduce obesity and obesity related diseases. The search of molecules capable to reduce the metabolic changes in plasma lipids, liver triglycerides leading to weight loss is a widely accepted approach to reduce the burden of obesity. Recently, it has been shown in vitro that, the water-soluble polysaccharides from common mushroom exerts a fat trapping activity on blood lipids through the formation of a cationic polymer capable to trap anionic complex substances as fat [27]. For such purpose, a double-blind vs placebo study was conducted to assess the safety and effectiveness of H2Oslim ${ }^{\circledR}$ on reducing cholesterols levels and weight in overweight healthy population.

\section{Materials and methods}

\section{Study design/intervention}

The study was a randomized, double-blind vs placebocontrolled design for 12 weeks. Volunteers (44 men/ 56 women) were randomly divided into two groups - placebo (P-group) or H20SLim (H-group). The participants consumed one capsule of placebo or one capsule of H2OSLim (containing $400 \mathrm{mg}$ ) 5-15 minutes before lunch throughout the study period.

\section{Test materials}

H20slim $\AA$, in high density form, was kindly provided by Tradichem SL (Madrid, SPAIN). The Vcaps 00 hard capsules were manufactured at Clean Rooms by Quimifarma 2007 SL, (Yuncos, Toledo, SPAIN) with an automatic IMA Zanasi 40E capsule filler (IMA SpA, Bologna Italy). The identical-looking placebo and active formulation capsules contained, respectively, $400 \mathrm{mg}$ of maize maltodextrin-based powder, or 400 mg H2Oslim $\AA-H D$

\section{Cohort}

The 100 participants (mean age 36, range 25-51,), BMI 25-30 (mean BMI 28,6) were divided into 2 groups. 50 were randomly assigned to P-Group (placebo) and 50 to H-Group (H2Oslim®). Of these initial 100 volunteers, 94 completed the 12-week study: 44 from the P-group, and 50 from the $\mathrm{H}$ group. Four volunteers dropped out of the study because they did not show a rapid weight loss $(n=4)$. There was not a reason given by the other two $(n=2)$.

\section{Food Intake}

The daily energy intake in both groups during the study was 2200-2700 kcal. Seven-day dietary and activity assessment of the subjects at baseline showed similar food intake habits and energy levels. No major dietary intervention or formal physical activity program was instituted during the course of the study; participants were instructed to maintain the current level of physical activity prior to study randomization during the course of the study

\section{Sample collection}

Fasting blood samples (5 ml of blood) were collected at baseline, and at 4, 8, and 10 weeks. Serum obtained from each blood sample was split into multiple $500 \mu \mathrm{l}$ aliquots and stored at $-20^{\circ} \mathrm{C}$ until needed for the measurement of total cholesterol and LDL cholesterol.

\section{Primary outcome}

Body Mass Index (BMI) and waist circumference was registered at the beginning, midpoint, and end of each intervention period by qualified staff. Systolic and diastolic blood pressures was also determined three times at 5-min intervals while volunteers are seated using a standardized mercury sphygmomanometer, to assess the ability of changes in blood pressure

\section{Statistical analysis}

Data analyses were collected at the end of each intervention; therefore, a replacement or substitution of a withdrawal subject was not planned; therefore, the missing data was considered unavailable data. The normality of variables as blood pressure were assessed. Variables not following a normal distribution will be transformed. Normal variables will be expressed as the mean and standard error of the mean. An intention-to-treat analysis will be performed for the analysis of efficacy. In order to determine differences in basal characteristics, a paired t-test will be used. Carryover effects will be assessed by three-way ANOVA. A general lineal model for repeated measurements will be performed to evaluate differences between variables at the beginning, mid- point, and end of each intervention period. Two-way ANOVA was used to determine the influence of treatment (active or placebo) and time on the continuous dependent variables. Statistical analyses was performed using IBM SPSS statistics $\mathrm{v}$ [22].

\section{Baseline data}

\begin{tabular}{|c|c|c|}
\hline \multicolumn{1}{|l|}{ Table 1: Baseline data. } & Group & Baseline \\
\hline Variables & Placebo (P) Active (H) & $93,4 \pm 6,394,9 \pm 5,1$ \\
\hline Weight $(\mathrm{Kg})$ & Placebo (P) Active (H) & $104,6 \pm 3,6105,1 \pm 4,0$ \\
\hline Waist $(\mathrm{cm})$ & Placebo (P) Active (H) & $155,2 \pm 18,3 \quad 151,1 \pm 16,5$ \\
\hline Total cholesterol $(\mathrm{mg} / \mathrm{dl})$ & Placebo (P) Active (H) & $85,7 \pm 6,388,2 \pm 5,1$ \\
\hline LDL-cholesterol $(\mathrm{mg} / \mathrm{dl})$ & &
\end{tabular}


The body weight and waist circumferences of the two groups shown no significant differences at baseline (Table 1). Baseline levels of serum lipids were similar in the two groups (Table 1).

\section{Adverse events}

The supplementation of $\mathrm{H} 20 \operatorname{sim}{ }^{\circledR}$ was well-tolerated. Intestinal flatulence was reported in five participants, 2 in the P-Group ( $\mathrm{n}=2)$ and 3 in the H-Group (n=3).

\section{Results}

The 100 participants (mean age 36, range 25-51,), BMI 25-30 (mean BMI 28,6) were divided into 2 groups and randomly assigned to placebo (p-group) and to active group(H-group). The mean daily energy intake in both groups was $2535 \pm 101 \mathrm{kcal}$. One week dietary and activity assessment of the subjects at baseline showed similar food intake habits and energy levels. Baseline characteristics of the two groups were well- matched and without significant differences at baseline (Table1). There were no significant differences in the baseline body weight, waist circumference, cholesterol level and ldl-cholesterol level measurements between the $\mathrm{P}$ and $\mathrm{H}$ groups (Table1). Significant differences were observed between the placebo group and the experimental intervention group were observed at the end of the study, respectively, for body weight (93.0kg vs. 88,9kg, p < 0.01), and waist circumference (102.9 cm vs. $92.2 \mathrm{~cm}$, respectively, $\mathrm{p}<0.05$ ).

At w8 the test results for waist circumference was quite significant statistically. The pattern of relative changes in weight and waist circumference was found to be different between the two groups and consistent with a difference in response to the intake of the active. These variables decreased from baseline, though at different rates and magnitudes associated with duration of the study, with the experimental group showing statistically significant changes compared with the placebo group from week 4 to week12 (Table2). Regarding blood lipids, significant differences were observed between the two groups as the study progressed with the $\mathrm{H}$ group showing greater improvement. At w12, significant differences were observed for total cholesterol $(\mathrm{p}<0.05)$ and LDL cholesterol $p<0.01$ ). Total cholesterol decreased by $0,02 \%$ in the p-group as opposed to $13.97 \%$ for the h2Oslim ${ }^{\circledR}$ group while LDL cholesterol levels fell by $0,01 \%$ in the placebo compared to $30,95 \%$ in the H-group.

\begin{tabular}{|c|c|c|c|c|c|c|}
\hline Variable & Group & Baseline & W4 & w8 & W12 & Change \\
\hline Weight (kg) & Placebo $(\mathrm{P})$ Active $(\mathrm{H})$ & $93,4 \pm 6,394,9 \pm 5,1$ & $93,1 \pm 4,0 \quad 92,3 \pm 2,9$ & $\begin{array}{c}92,9, \pm 3,3 \\
90,9 \pm 2,1\end{array}$ & $\begin{array}{l}93,0 \pm 2,3 \\
88,9 \pm 1,1\end{array}$ & $\begin{array}{l}-0,4 \\
-5,0\end{array}$ \\
\hline Waist $(\mathrm{cm})$ & Placebo $(\mathrm{P})$ Active $(\mathrm{H})$ & $104,6 \pm 3,6105,1 \pm 4,0$ & $103,4 \pm 6,3 \quad 98,9 \pm 5,1$ & $\begin{array}{c}103,0 \pm 3,0 \\
94,5 \pm 2,7\end{array}$ & $\begin{array}{c}102,9 \pm 4,1 \\
92,2 \pm 1,9\end{array}$ & $\begin{array}{r}-1,7 \\
-12,9\end{array}$ \\
\hline Total-Chol (mg/dl) & Placebo (P) Active $(\mathrm{H})$ & $155,2 \pm 18,3151,1 \pm 16,5$ & $150, \pm 11,1132,8 \pm 15,5$ & $\begin{array}{c}153,6+14,4 \\
121,6 \pm 9,0\end{array}$ & $\begin{array}{l}152,1 \pm 6,1 \\
113,0 \pm 4,4\end{array}$ & $\begin{array}{r}-3,1 \\
-21,1\end{array}$ \\
\hline LDL- Chol(mg/dl) & Placebo (P) Active $(\mathrm{H})$ & $85,7 \pm 6,388,2 \pm 5,1$ & $85,1 \pm 3,3 \quad 74,2 \pm 2,1$ & $\begin{array}{l}84,8 \pm 2,6 \\
65,0 \pm 3,8\end{array}$ & $\begin{array}{l}84,9 \pm 2,2 \\
60,9 \pm 1,1\end{array}$ & $\begin{array}{r}-0,8 \\
-27,3\end{array}$ \\
\hline
\end{tabular}

\section{Discussion}

The present study revealed that water soluble polysaccharides from Agaricus bisporus, Is a safe strategy in reducing body weight in overweight and/or obese subjects. The current clinical study shows that $\mathrm{H} 2 \mathrm{O}$ slim ${ }^{\circledR}$ administration is associated with a decrease in the blood lipid levels in comparison with the placebo group. These observations support the idea that the weight reduction effect of $\mathrm{H} 2 \mathrm{Oslim} \circledast$ is mediated by its direct effect on lipid trapping [27].Chitosan, the non-water soluble linear polysaccharide composed of randomly distributed $\beta-(1 \rightarrow 4)$-linked D-glucosamine (deacetylated unit) and $\mathrm{N}$-acetyl-D-glucosamine (acetylated unit) made by treating the chitin shells of shrimp and other crustaceans polysaccharides has traditionally been studied as an agent for lowering weight and cholesterol since it is not well digested in the human body. Chitosan appears to bond with fatty compounds in the digestive tract, carrying them out in the faeces [28]. A number of human trials have reached different conclusions concerning the effect of chitosan on weight loss.
Although early studies conducted with hypocaloric diets suggested that chitosan could a significant effect on body weight, later and larger clinical trials $(n=250)$ showed no effect at all when compared to a placebo in obese population [29]. Since then, the efficacy of chitosan has been investigated at different doses and also when administered concomitantly with a calorie-restricted diet and physical activity in various short-term and mediumterm studies, and therefore the effectivity of non-soluble linear polysaccharides has been disputed. By contrast, the results here presented show specifically that the water-soluble polysaccharides isolated from the common mushroom, Agaricus bisporus, do have a direct impact on weight loss and waist circumference.

The 12 weeks double blind vs placebo study revealed that a solely $400 \mathrm{mg}$ dosage is capable of reducing significantly both variables with a deeper impact on waist circumference. This data together with the total cholesterol and ldl-cholesterol data analysis seems to reveal that the mechanism previously suggested about the fat trapping properties of the water-soluble polysaccharides 
net [27] is linked to the weight loss effect. According to previous studies [30], adipose tissue plays a prominent role in the clinical expression of metabolic syndrome, most likely mediated by the increased release and peripheral tissue action of non-esterified fatty acids and by the dysregulated production of adipocytesecreted proteins, including leptin, adiponectin, resistin, TNF- $\alpha$, and IL-6. The observation of a significant weight loss, as well as a decrease in cholesterol levels is consistent with early reports in the literature observing the association [31]. The current results suggest that $\mathrm{H} 2 \mathrm{Oslim}{ }^{\circledR}$ may be a helpful adjunct in the management of overweight. Further studies need to be processed in order to understand the direct impact of the H2Oslim ${ }^{\circledR}$ intake together with a healthy lifestyle on overweight people. Additional studies are needed to corroborate these initial first results.

\section{References}

1. Singh GM, Danaei G, Farzadfar F, Stevens GA, Woodward M, et al (2013) The age-specific quantitative effects of metabolic risk factors on cardiovascular diseases and diabetes: a pooled analysis. PLoS One 8(7): e65174.

2. Czernichow S, Kengne AP, Stamatakis E, Hamer M, Batty GD, et al. (2011) Body mass index, waist circumference and waist-hip ratio: which is the better discriminator of cardiovascular disease mortality risk? Evidence from an individual-participant meta-analysis of 82864 participants from nine cohort studies. Obes Rev 12(9): 680-687.

3. Lauby Secretan B, Scoccianti C, Loomis D, Grosse Y, Bianchini F, et al (2016) Body fatness and cancer viewpoint of the IARC working group. N Engl J Med 375(8): 794-798.

4. Anandacoomarasamy A, Caterson I, Sambrook P, Fransen M, March L, et al. (2008) The impact of obesity on the musculoskeletal system. Int J Obes 32(2): 211-222.

5. Anstey K, Cherbuin N, Budge M, Young J (2011) Body mass index in midlife and late-life as a risk factor for dementia: a meta-analysis of prospective studies. Obes Rev 12(5): e426-e37.

6. Kushner RF, Foster GD (2000) Obesity and quality of life. Nutrition16(10): 947-952.

7. Goettler A, Grosse A. Sonntag D (2017) Productivity loss due to overweight and obesity: a systematic review of indirect costs. BMJ open 7(10): e014632.

8. Hill JO, Peters JC, Catenacci VA, Wyatt HR (2008) International strategies to address obesity. Obesity reviews: an official journal of the International Association for the Study of Obesity 9(Suppl 1): 41-47.

9. World Health Organization (2008) World Health Statistics, France.

10. Lakerveld J, Mackenbach J (2017) The upstream determinants of adult obesity. Obesity facts 10(3): 216-22.

11. Harding JL, Backholer K, Williams ED, Peeters A, Cameron AJ, et al. (2014) Psychosocial stress is positively associated with body mass index gain over 5 years: evidence from the longitudinal AusDiab study. Obesity (Silver Spring) Md 22(1): 277-286.

12. Patel SR, Hu FB (2008) Short sleep duration and weight gain: a systematic review. Obesity (Silver Spring, Md) 16(3): 643-653.

13. Affenito SG, Franko DL, Striegel Moore RH, Thompson D (2012) Behavioral determinants of obesity: research findings and policyimplications. J Obes 150732 .
14. Block JP, He Y, Zaslavsky AM, Ding L, Ayanian JZ, et al. (2009) Psychosocial stress and change in weight among US adults. Am J Epidemiol 170(2): 181-192.

15. Kiecolt Glaser JK, Newton TL (2001) Marriage and health: his and hers. Psychol Bull 127(4): 472-503.

16. Zamani Sani SH, Eskandarnejad M, Fathirezaie Z (2016) Body image, perceived physical fitness, physical activity, body mass index and age in women. Women Health Bull 3(3): e31886.

17. Han LK, Sumiyoshi M, Zheng YN, Okuda H, Kimura Y, et al. (2003) Antiobesity action of Salix matsudana leaves (Part 2). Isolation of anti-obesity effectors from polyphenol fractions of Salix matsudana. Phytother Res 17(10): 1195-1198.

18. Yu SF, Shun CT, Chen TM, Chen YH (2006) 3-O-beta-D-glucosyl-(1N6)- beta-D-glucosyl-kaempferol isolated from Sauropus androgenus reduces body weight gain in Wistar rats. Biol Pharm Bull 29(12): 25102513.

19. Kwon O, Eck P, Chen S, Corpe CP, Lee JH, et al. (2007) Inhibition of the intestinal glucose transporter GLUT2 by flavonoids. FASEB J 21(2): 366377.

20. Kim HK, Nelson Dooley C, Della Fera MA, Yang JY, Zhang W, et al. (2006) Genistein decreases food intake, body weight, and fat pad weight and causes adipose tissue apoptosis in ovariectomized female mice. J Nutr 136(2): 409-414.

21. Naaz A, Yellayi S, Zakroczymski MA, Bunick D, Doerge DR, et al. (2003) The soy isoflavone genistein decreases adipose deposition in mice. Endocrinology 144(8): 3315-3320.

22. Dang Z, Lowik CW (2004) The balance between concurrent activation of ERs and PPARs determines diadzein-induced osteogenesis and adipogenesis. J Bone Miner Res 19(5): 853-861.

23. Tsuda T, Ueno Y, Kojo H, Yoshikawa T, Osawa T, et al. (2005) Gene expression profile of isolated rat adipocytes treated with anthocyanins. Biochim Biophysica Acta 1733(2-3): 137-147.

24. Preuss HG, Wallerstedt D, Talpur N, Tutuncuoglu SO, Echard B, et al. (2000) Effects of niacin-bound chromium and grape seed proanthocyanidin extract on the lipid profile of hypercholesterolemic subjects: a pilot study. J Med 31(5-6): 227-246.

25. Nakagawa Y, Iinuma M, Matsuura N, Yi K, Naoi M, et al. (2008) A potent apoptosis-inducing activity of a sesquiterpene lactone, S Rayalam, et al. (Eds.) Journal of Nutritional Biochemistry 19: 717-726 723.

26. Wolfram S, Raederstorff D, Preller M, Wang Y, Teixeira SR, et al. (2006) Epigallocatechin gallate supplementation alleviates diabetes in rodents. J Nutr 136 (10): 2512-2518.

27. Marañón JA, Muñoz Plaza D, Lozano C (2019) Natural Approaches for Reducing Risk Markers of Cardiovascular Diseases Related to Obesity. Am J Biomed Sci \& Res 5(4): 325-328.

28. Jull AB, Bennett DA, Dunshea Mooij CA, Rodgers A (2008). Chitosan for overweight or obesity. Cochrane Database Syst. Rev 3: CD003892.

29. Ni Mhurchu C, Poppitt SD, McGill AT, Leahy FE, Bennett DA, et al. (2004) The effect of the dietary supplement, chitosan, on body weight: A randomised controlled trial in 250 overweight and obese adults. Int. J. Obes 28(9): 1149-1156.

30. McTernan CL, McTernan PG, Harte AL, Levick PL, Barnett AH, et al. (2002) Resistin, central obesity, and type 2 diabetes. Lancet 359: 46-47.

31. Richmond W (1973) Preparation and properties of a cholesterol oxidase from Nocardia sp. and its application to the enzymatic assay of total cholesterol in serum. Clin Chem 19(12): 1350-1356. 